\title{
Analisa Pengereman Dinamik Pada Motor Brushless DC (BLDC)
}

\author{
1Galih Rakasiwi 2Slamet Riyadi \\ Teknik Elektro, Fakultas Teknik, Universitas Katolik Soegijapranata \\ Semarang \\ 1rakasiwi.galih0406@gmail.com, 2sriyadi7167@gmail.com
}

\begin{abstract}
Abstrak
Seiring dengan perkembangan zaman, teknologi dengan menggunakan motor listrik mengalami kemajuan yang sangat pesat khususnya di bidang transportasi elektrik. Salah satu jenis motor yang digunakan untuk transportasi elektrik yaitu motor Brushless DC (BLDC) karena memiliki efisiensi tinggi, torka besar, kecepatan tinggi dan biaya operasional yang murah. Pada kendaraan listrik yang digerakkan oleh motor BLDC dibutuhkan suatu sistem keamanan yaitu pengereman. Dalam penelitian ini penulis mengusulkan salah satu metode pengereman pada motor BLDC. Pengereman pada motor BLDC dirancang secara dinamik, dimana motor BLDC dioperasikan sebagai generator yang digerakkan oleh motor DC. Dioda pada modul inverter dimanfaatkan untuk melakukan pengereman dinamik pada motor BLDC. Pengereman dinamik dilakukan dengan cara memberikan resistor pada terminal input motor BLDC, dimana langkah tersebut dilakukan secara tiga tahapan dengan cara memberikan resistansi yang berbeda. Pada saat terjadinya pengereman dinamik, nilai resistansi mempengaruhi lama waktu yang dibutuhkan untuk mencapai kondisi stasioner. Pada makalah ini dipaparkan hasil analisis pengereman dinamik pada motor BLDC.
\end{abstract}

Kata Kunci : transportasi elektrik, motor BLDC, pengereman dinamik, generator, resistansi

\section{Pendahuluan}

Seiring dengan perkembangan zaman, cadangan dan persediaan bahan bakar fosil setiap tahun semakin menipis. Hal ini sangat berpengaruh bagi dunia otomotif yang mengandalkan bahan bakar fosil sebagai sumber utama penggerak kendaraan bermotor. Saat ini banyak dijumpai kendaraan bermotor yang ramah lingkungan, salah satunya yaitu kendaraan elektrik atau listrik. Kendaraan listrik merupakan kendaraan yang menggunakan energi listrik sebagai energi penggeraknya. Pada awalnya motor DC digunakan untuk menggerakan kendaraan listrik, karena memiliki torka yang besar. Motor DC memiliki kelemahan pada sikat (brush). Hal ini menyebabkan gesekan pada motor DC sehingga motor DC membutuhkan perawatan yang tinggi untuk mengganti sikat. Oleh karena itu kebutuhan terhadap motor yang memiliki efisiensi tinggi, torka tinggi, kecepatan tinggi dan biaya operasional yang murah semakin meningkat. Untuk memenuhi kebutuhan tersebut digunakan Motor Brushless DC (BLDC) [1].

Motor Brushless DC (BLDC) banyak digunakan untuk kendaraan listrik sebagai pengganti motor DC karena motor BLDC memiliki karakteristik yang sama dengan motor DC. Motor BLDC juga tidak menggunakan sikat. Oleh karena itu motor BLDC banyak digunakan untuk aplikasi penggerak kendaraan listrik dan industri. Salah satu kebutuhan utama yang dibutuhkan pada kendaraan listrik yaitu pengereman. Terdapat tiga jenis pengereman pada kendaraan elektrik yaitu pengereman secara dinamik, pengereman secara plugging, dan pengereman secara regeneratif.

Pada makalah ini dijelaskan pengereman pada motor BLDC secara dinamik. Pada pengereman dinamik energi pengereman terbuang menjadi energi panas pada resistor. Pengereman dinamik menghasilkan pengereman yang halus dan tidak ada hentakan sehingga tidak menimbulkan kerugian. Dalam pengereman dinamik, lama waktu pengereman ditentukan oleh nilai resistor yang diberikan ke belitan stator dan kapasitas motor. Metode pengereman dinamik memiliki keuntungan antara lain kemudahan untuk mengatur kecepatan pengereman terhadap motor BLDC.

\section{Metodologi Penelitian}

Motor BLDC adalah jenis motor sinkron dengan menggunakan magnet permanen pada rotor dan kumparan stator[1,4]. Motor BLDC memiliki biaya operasional yang lebih murah dari motor DC dan memiliki kecepatan yang lebih tinggi serta memiliki torsi awal yang besar. Meskipun demikian pengendalian motor BLDC jauh lebih kompleks dan memakan biaya yang cukup mahal. 


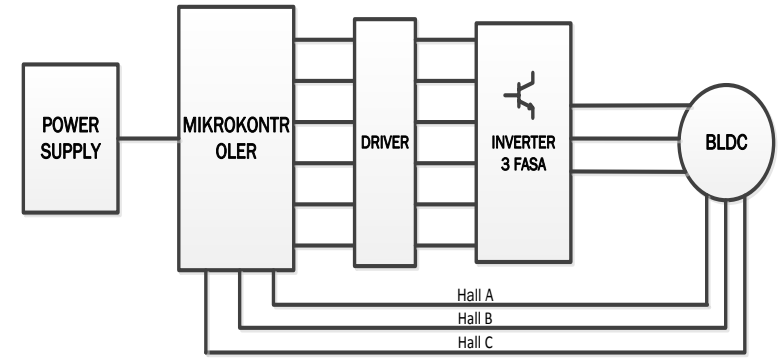

Gambar 1. Diagram blok pengendalian motor BLDC

Kontruski motor BLDC terdiri dari stator yang berupa belitan dan rotor yang menggunakan magnet permanen. Stator merupakan bagian yang diam atau statis, fungsinya sebagai pembangkit elektromagnetik untuk menghasilkan medan elektromagnet pada motor. Sedangkan rotor adalah bagian dari motor yang berputar karena adanya gaya tarik menarik atau tolak menolak antara stator dan rotor. Pada motor BLDC, kontroler berfungsi untuk mengatur arus masukan yang harus dialirkan ke stator untuk dapat menimbulkan medan elektromagnet yang sesuai untuk memutar rotor. Motor BLDC juga dilengkapi dengan sensor hall effect untuk membaca posisi rotor.

\subsection{Pengereman Dinamik}

Pengereman dinamik merupakan salah satu metode pengereman pada motor listrik yang sangat praktis dan memberikan gaya pengereman yang sangat baik. Dengan alasan itu maka pengereman dinamik sangat baik digunakan pada sistem pengereman untuk waktu yang sangat singkat karena motor dapat berhenti dengan cepat. Pengereman ini dilakukan dengan cara memutuskan suplai tegangan ke sebuah motor yang sedang berputar lalu dihubungkan dengan sebuah beban pada terminal statornya. Intensitas pengereman tergantung dari arus yang diberikan pada terminal stator dan dengan menentukan tahanan.

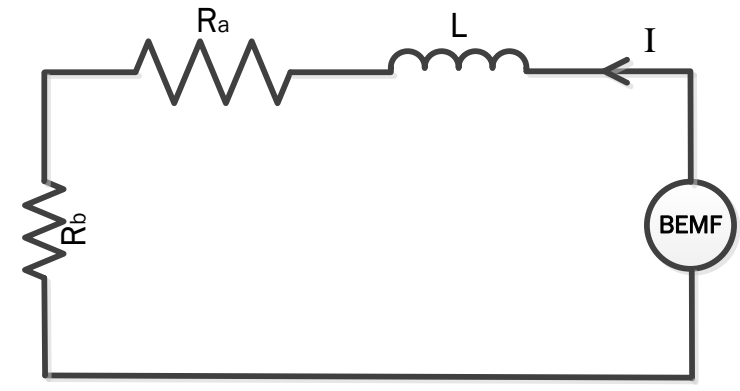

Gambar 2. Rangkaian ekivalen motor BLDC

Untuk menghitung besarnya tahanan pada pengereman dinamik dapat dilihat dari persamaan berikut ini :

$$
E=I(R a+R b)
$$

Tahanan untuk pengereman dinamik :

$$
\mathrm{Rb}=\frac{\mathrm{E}}{\mathrm{l}}-\mathrm{Ra}
$$

Arus untuk pengereman dinamik :

$$
I=\frac{E}{R a+R b}
$$

Ketika sebuah motor yang sedang berputar dilepaskan dari sumber, motor tersebut masih memiliki energy kinetik karena motor masih berputar. Besar energi listrik yang dibangkitkan tergantung pada kecepatan motor saat sumber tersebut dilepaskan, karena energi sisa pada belitan medan dan putaran masih ada sehingga motor akan beroperasi sebagai generator yang mengalirkan arus menuju beban. Keadaan ini menyebabkan energi yang dihasilkan oleh stator akibat dari putaran akan dilepas melalui beban dalam bentuk panas.

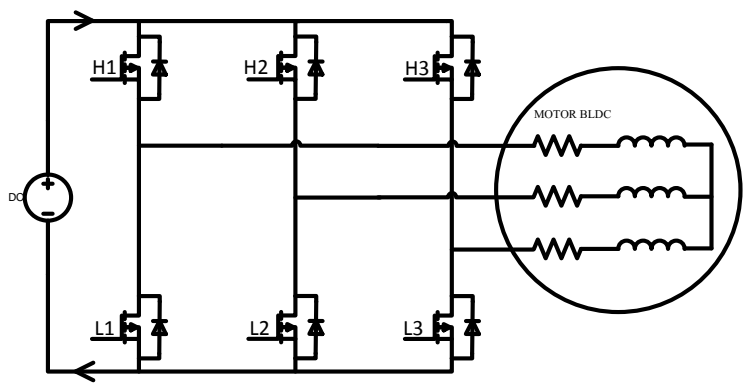

Gambar 3. Rangkaian ekivalen motor BLDC pada saat motoring

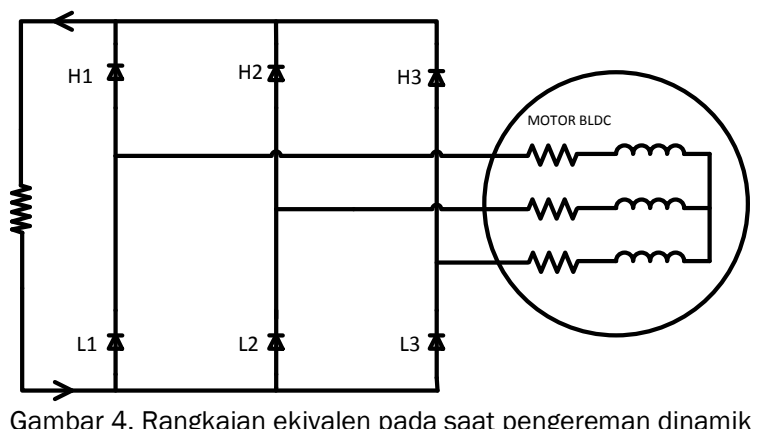

Rangkaian pengereman dinamik pada penelitian ini membuat semua saklar pada posisi mati, sehingga motor BLDC akan beroperasi sebagai generator. Pengereman dinamik dilakukan dengan menggunakan beberapa buah resistor untuk mengetahui respon motor pada saat terjadi pengereman.

\section{Hasil Simulasi dan Pengujian}

Pengereman dinamik pada motor BLDC telah disimulasikan dalam perangkat lunak PSIM. Pada 
simulasi, saat terjadi pengereman dinamik saklar pada inverter dalam posisi mati. Dari hasil simulasi yang telah diperoleh, semakin kecil resistor maka arus yang dihasilkan akan semakin besar. Hasil dari gelombang output ditunjukan pada gambar berikut.
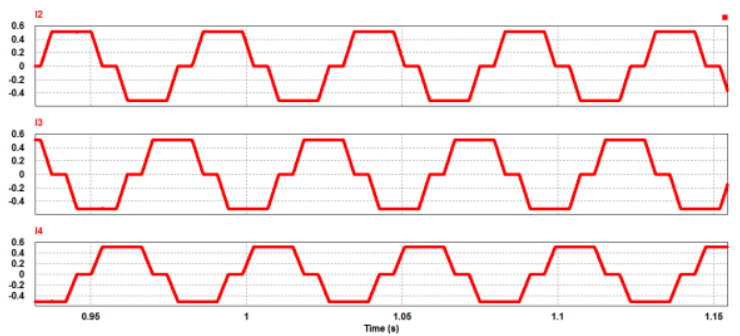

Gambar 5. Hasil simulasi gelombang arus dengan beban $15 \Omega$
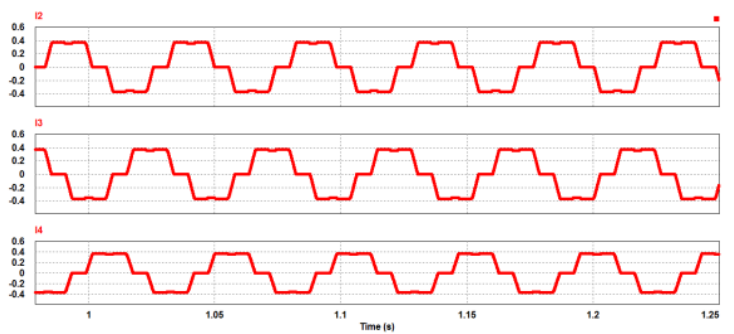

Gambar 6. Hasil simulasi gelombang arus dengan beban $30 \Omega$

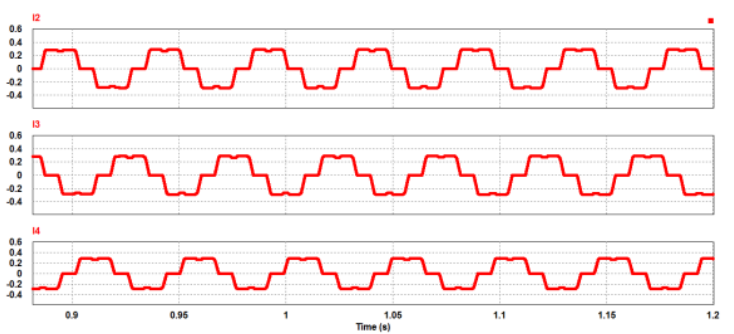

Gambar 7. Hasil simulasi gelombang arus dengan beban $45 \Omega$

Pengereman dinamik pada motor BLDC telah disimulasikan dan dibuat prototype di laboratorium. Motor BLDC dioperasikan sebagai generator. Untuk mengoperasikan motor BLDC sebagai generator digunakan motor DC sebagai penggeraknya.

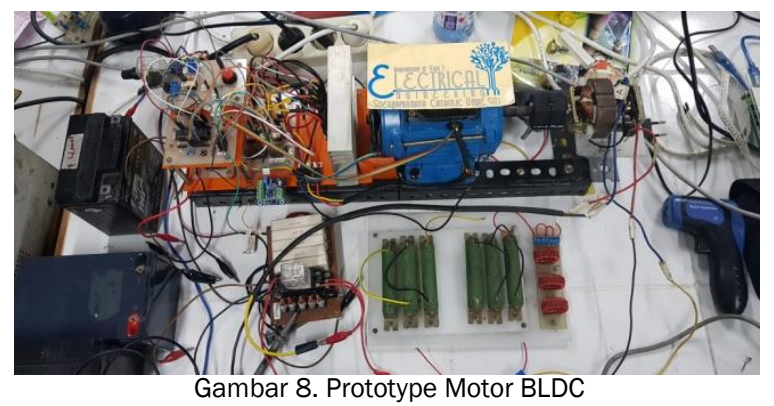

Motor DC diputar pada kecepatan yang konstan. Setelah motor DC berputar menggerakan motor BLDC sebagai generator, selanjutnya terminal input pada motor BLDC akan diberikan resistor.
Pada pengujian ini, terminal input motor BLDC akan diberi resistor $15 \Omega, 30 \Omega$, dan $45 \Omega$. Kecepatan awal pada saat motoring atau sebelum terjadi pengereman $1313 \mathrm{rpm}$. Berikut ini adalah hasil pengujian arus setiap fasa dengan resistor $15 \Omega, 30 \Omega$, dan $45 \Omega$.

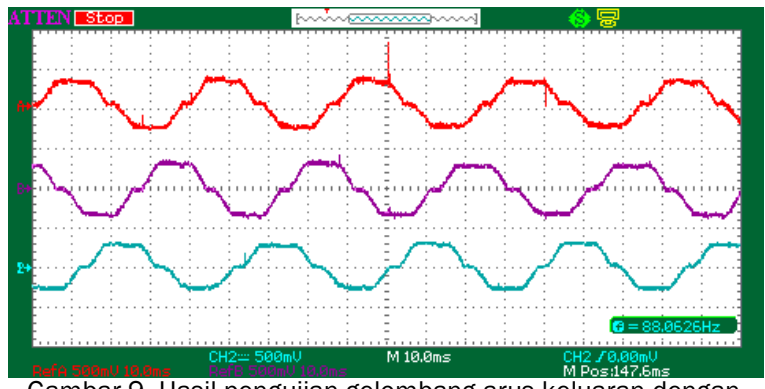

Gambar 9. Hasil pengujian gelombang arus keluaran dengan beban $15 \Omega$

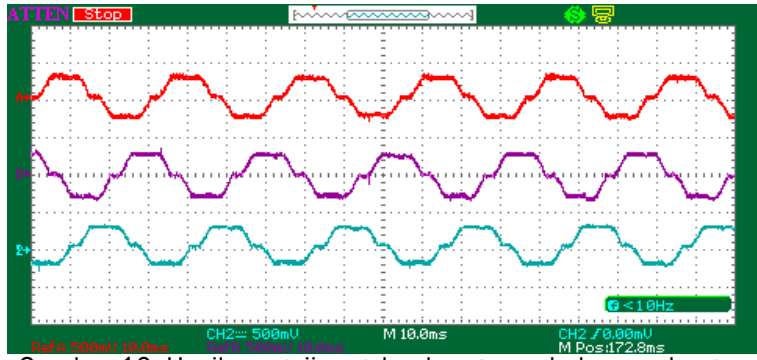

Gambar 10. Hasil pengujian gelombang arus keluaran dengan beban $30 \Omega$

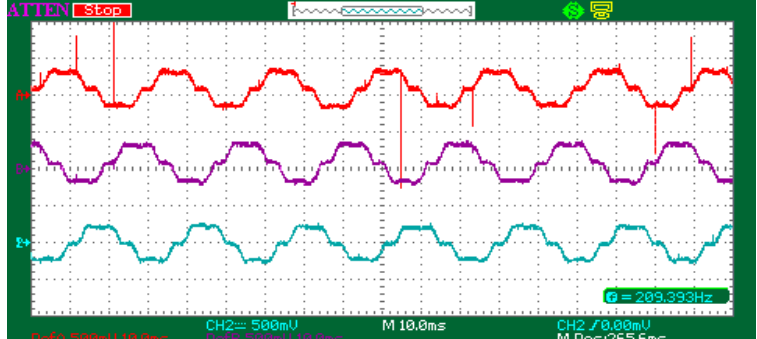

Gambar 11. Hasil pengujian gelombang arus keluaran dengan beban $45 \Omega$

Tegangan setiap fasa dengan resistor $15 \Omega$ ditunjukkan pada gambar 12, tegangan fasa dengan resistor $30 \Omega$ ditunjukkan pada gambar 13 , dan tegangan setiap fasa dengan resistor $45 \Omega$ ditunjukkan pada gambar 14 .

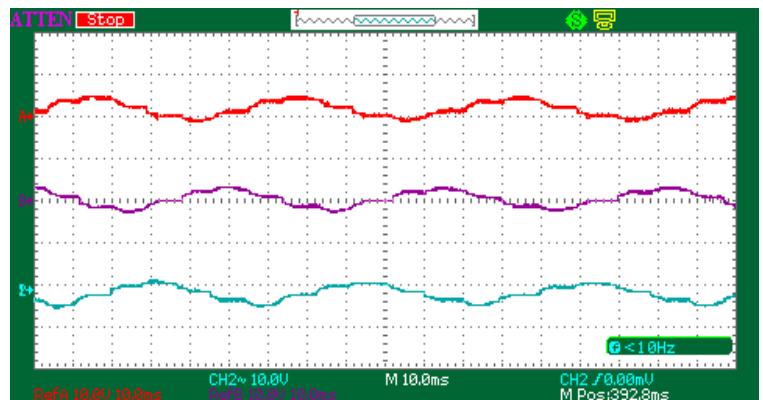

Gambar 12. Hasil pengujian gelombang tegangan keluaran dengan beban $15 \Omega$ 


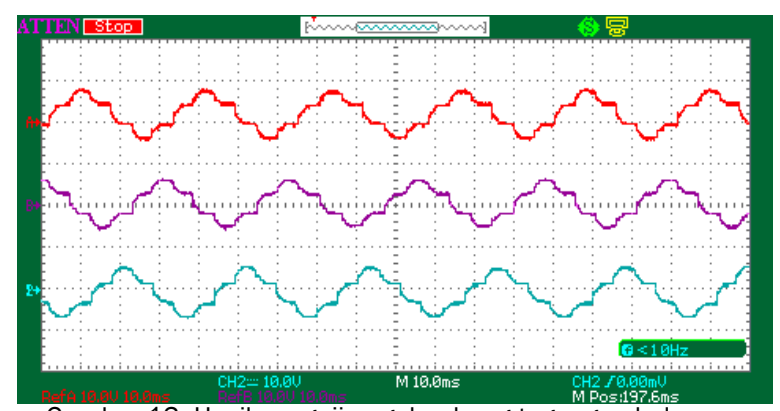

Gambar 13. Hasil pengujian gelombang tegangan keluaran dengan beban $30 \Omega$

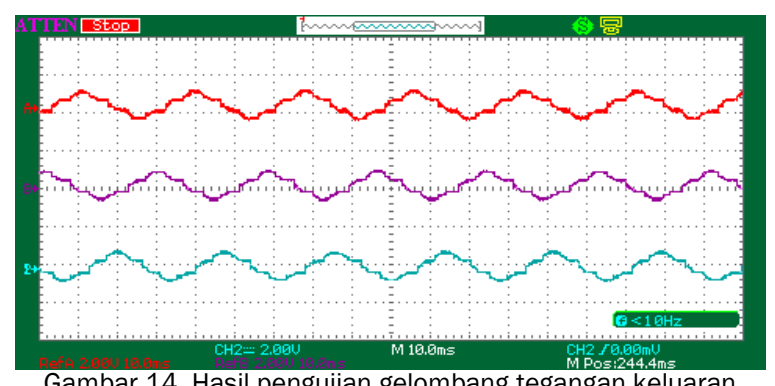

Gambar 14. Hasil pengujian gelombang tegangan keluaran dengan beban $45 \Omega$ (skala tegangan $\times 10$ )

\section{Hasil Perbandingan Arus}

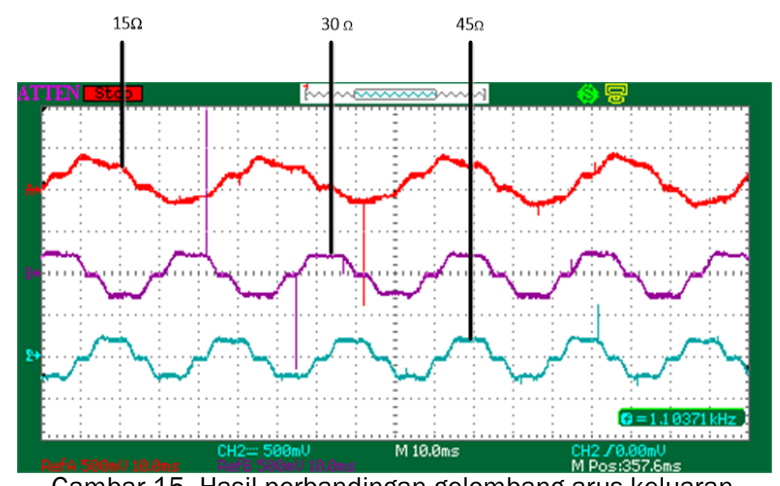

Gambar 15. Hasil perbandingan gelombang arus keluaran

Setelah dilakukan pengujian untuk pengereman dinamik dengan memberi resistor pada tegangan input motor BLDC secara tiga tahap yaitu $15 \Omega, 30$ $\Omega$, dan $45 \Omega$ hasil dari pengujian dapat digunakan untuk dianalisa dan ditarik kesimpulan. Hasil yang diperoleh menjadi perbandingan antara pengereman dinamik dengan beban $15 \Omega, 30 \Omega$, dan $45 \Omega$.

Tabel 1. Hasil Pengujian

\begin{tabular}{|c|c|c|}
\hline No & Resistor $(\Omega)$ & Kecepatan (rpm) \\
\hline 1 & $15 \Omega$ & $391 \mathrm{rpm}$ \\
\hline 2 & $30 \Omega$ & $458 \mathrm{rpm}$ \\
\hline 3 & $45 \Omega$ & $549 \mathrm{rpm}$ \\
\hline
\end{tabular}

\section{Nomenklatur}

E : Tegangan pada saat pengereman dinamik

I : Arus pada saat pengereman dinamik

Ra : Tahanan stator motor

Rb : Tahanan Pengereman

\section{Kesimpulan}

Jika nilai resistor yang dipasang pada motor BLDC kecil maka arus pada saat pengereman akan besar sehingga waktu yang dibutuhkan untuk terjadi pengereman semakin cepat dan kecepatannya turun lebih cepat, jika semakin besar nilai resistor yang dipasang pada motor BLDC maka nilai arus pada saat pengereman kecil sehingga membutuhkan waktu yang lama untuk terjadi pengereman. Semakin besar arus pada pengereman maka waktu pengereman akan semakin cepat.

\section{Daftar Pustaka}

[1] Fauzi Yuda Pratama, Endrayansyah, “Rancang Bangun Pengendalian Kecepatan Brushless DC Motor Tipe A2212/10T 1400 Kv Menggunakan Kontroller PID Berbasis Labview", Universitas Negeri Surabaya, Vol. 7, No. 3 Tahun 2018, 157-166

[2] Zhao, Jian., Yu, Yangwei, "Brushless DC Motor Fundamentals", Application Note, AN047. 2011

[3] Agung Dwi Yulianta, Sasongko Pramono Hadi dan Suharyanto, "Pengendalian Kecepatan Motor Brushless DC (BLDC) menggunakan Metode Logika Fuzzy", Jurnal Sains, Teknologi dan Industri, Vol. 12, No. 2, 2015

[4] Achmad Fachrudin Istiananda, Ir. Rusdhianto Effendie A.K. M.T., dan Andri Ashfahani S.T. M.T. M.Sc. "Perancangan dan Implementasi Sistem Pengaturan Kecepatan Motor Arus Searah Tanpa Sikat Menggunakan Metode PID-Robust", Jurnal Teknik ITS Vol. 5, No. 2, (2016) ISSN : 2337-3539

[5] Md. Rifat Hazari, Effat Jahan, "Design of a Brushless DC (BLDC) Motor Controller", International Conference on Electrical Engineering and Information \& Communication Technology (ICEEICT), 2014 
[6] Y.B. Adyapaka Apatya, Aries Subiantoro, Feri Yusivar, "Design and Prototyping of 3-phase BLDC motor", 2017 15 th International Conference on Quality in Research (QiR) : International Symposium on Electrical and Computer Engineering

[7] EATON Corporation, “Dynamic Braking”, Application Note AP040010EN, 2013

[8] Muhammad Hami Pradipta, Tedjo Sukmadi, dan Mochammad Facta, "Pengereman Dinamis Konvensional Pada Motor Induksi Tiga Fasa", Universitas Diponegoro Semarang, Transient, Vol. 3, No. 4, 2014, ISSN : 2302-9927,657

[9] Moch. Faishol Yusron, Joko, "Pengereman Dinamik Motor Induksi 3 Fase 220V/380V", Jurnal INAJEEE, Vol. 1, No. 1, 2018

[10] Ri Munarto, Bobby Rinaldi, "Analisis Pengereman Dinamik pada Motor Induksi 3 Fasa dengan Metode Injeksi Arus Searah dan Kapasitor Eksitasi Sendiri Fuzzy C-Means Clustering", Jurnal SETRUM, Vol. 7, No. 1, 2018, p-ISSN : 2301-4652 